\title{
Native Air-Formed Oxide Film and its Effect on Magnesium Alloys Corrosion
}

\author{
S. Feliu Jr., ${ }^{* 1}$ J.C. Galván ${ }^{1}$, A. Pardo ${ }^{2}$, M.C. Merino ${ }^{2}$ and R. Arrabal ${ }^{2}$

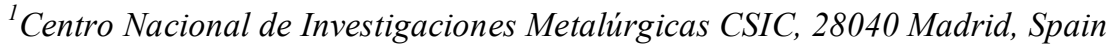 \\ ${ }^{2}$ Departamento de Ciencia de Materiales, Facultad de Química, Universidad Complutense, 28040 Madrid, Spain
}

\begin{abstract}
The present work uses X-ray photoelectron spectroscopy (XPS) analysis to compare the chemical composition of native oxide films formed spontaneously on commercial pure magnesium and AZ31, AZ80 and AZ91D magnesium alloys. The study considers both the outer surface and inner regions of the films with the assistance of argon ion bombardment. Possible relationships are established between the alloy Al content and the native oxide film characteristics. The Al content is very similar in the oxide films on all three studied alloys. XPS identifies a much greater film thickness on AZ80 and AZ91D specimens than on AZ31 and pure Mg specimens, which seems to be related with the presence of $\beta$ phase $\left(\mathrm{Mg}_{17} \mathrm{Al}_{12}\right)$ on the AZ91D alloy surface and of the eutectic $\alpha-\mathrm{Mg} / \beta$ on the AZ80 alloy surface. Considerable $\mathrm{Ca}$ segregation is observed (directly related with the calcium impurities content in the bulk material) towards the outer surface of the metal, where it appears in the form of calcium oxide. Direct correspondence is found between the thickness of the native oxide film formed spontaneously on the surface of magnesium and its alloys and their subsequent corrosion resistance in exposure to a $3.5 \mathrm{wt} \% \mathrm{NaCl}$ solution.
\end{abstract}

Keywords: Magnesium alloys, native oxide film intermetallics, impurities, XPS.

\section{INTRODUCTION}

The chosen study materials, Mg-Al alloys, have drawn great scientific and technical interest in the last two decades. From a practical viewpoint, magnesium is the lowest density structural metal, making it highly attractive for use in the automotive, aerospace, IT and electronics industries, and for the development of new biomaterials for orthopaedic and cardiovascular applications, where weight plays a decisive role. However, magnesium is one of the most chemically active metals and its corrosion resistance is a key point limiting its use in real service conditions.

Despite the large number of papers published on the corrosion mechanisms of Mg-Al alloys, certain aspects of these materials still remain to be fully clarified. Many researchers have carried out studies to establish relationships between the alloy microstructure (amount and distribution of $\beta$ phase in alloys) or the Al content in the bulk alloy and its corrosion resistance [1-34]. Far fewer studies have addressed aspects related with the chemical composition of the thin native oxide films that form on the outer surface (thicknesses of the order of $3 \mathrm{~nm}$ ) in contact with the atmosphere or with solutions of low aggressivity [35-46]. Differences in the thickness and chemical composition of these films, as a function of the alloy microstructure and alloying element composition, can yield basic information about their formation on $\mathrm{Mg}$-Al alloys in the atmosphere or during immersion in saline solutions.

Many papers have reported impurity element segregation at or near the surface of magnesium and $\mathrm{Mg}$ alloys as a result

*Address correspondence to this author at the Centro Nacional de Investigaciones Metalúrgicas CSIC, 28040 Madrid, Spain; Fax: +34-91534-7425; E-mail: sfeliu@cenim.csic.es of the casting process. Minor contaminant elements (Fe, Ni and $\mathrm{Cu}$ ) precipitate as intermetallic phases when their solubility limit is exceeded. These intermetallic phases on the surface can act as galvanic cathodes and accelerate the alloy's corrosion process [1,2]. Nevertheless, although calcium is one of the commonest contaminants in many metals, no references have been found to superficial calcium enrichment on magnesium or $\mathrm{Mg}$ alloys as a consequence of the casting process. The greatest impediment to obtaining information on this phenomenon is that the segregation of $\mathrm{Ca}$ impurities (few ppm) towards the surface takes place in very thin layers (one monolayer), so thin that they are often inappreciable by conventional materials characterisation techniques (SEM/EDX or TEM) [47]. In this study the XPS technique has yielded highly promising results, since it allows the analysed thickness to be reduced to only $3 \mathrm{~nm}$ and provides information on the oxidation state of the detected element.

The present research has focused on four magnesium alloys selected to give specific and substantial differences in the surface chemistry of the oxide film formed after the casting process. As will be seen throughout the work, the behaviour of these alloys falls into two clearly differentiated groups: one formed by alloys AZ91D and AZ80, containing higher Al percentages; and the other formed by AZ31 and $99 \%$ pure $\mathrm{Mg}$ (Table 1). Each presents different possibilities regarding the segregation and oxidation tendencies of the alloying elements and the composition and distribution of intermetallic phase particles on the magnesium surface. The higher alloying element concentration in the AZ91D and AZ80 systems tends to promote the occurrence of second phase intermetallics on the surface and in the bulk. 
Table 1. Chemical Composition of Pure Mg and Mg-Al Alloys

\begin{tabular}{|c|c|c|c|c|c|c|c|c|c|c|}
\hline \multirow{2}{*}{ Material } & \multicolumn{10}{|c|}{ Elements (wt.\%) } \\
\hline & Al & $\mathbf{Z n}$ & Mn & $\mathbf{S i}$ & $\mathrm{Cu}$ & $\mathrm{Fe}$ & $\mathbf{N i}$ & $\mathrm{Ca}$ & $\mathbf{Z r}$ & Others \\
\hline $\operatorname{Mg}(99 \%)$ & 0.006 & 0.014 & 0.03 & 0.019 & 0.001 & 0.004 & $<0.001$ & 0.0026 & & \\
\hline AZ31 & 3.1 & 0.73 & 0.25 & 0.02 & $<0.001$ & 0.005 & $<0.001$ & 0.0014 & $<0.001$ & $<0.30$ \\
\hline AZ80 & 8.2 & 0.46 & 0.13 & 0.01 & $<0.001$ & 0.004 & & 0.0013 & & $<0.30$ \\
\hline AZ91D & 8.8 & 0.68 & 0.30 & 0.01 & $<0.001$ & 0.004 & $<0.008$ & 0.0014 & & $<0.30$ \\
\hline
\end{tabular}

The objectives of this research are as follows:

1. To study the chemical composition of the native oxide film that forms spontaneously on the surface of magnesium and AZ31, AZ80 and AZ91D alloys in the process of their obtainment. It will be attempted to find relationships between the alloying element contents in the bulk material, the thickness of the native oxide film formed, and the amount of $\mathrm{Al}$ segregated to the outer surface.

2. To analyse the segregation of $\mathrm{Ca}$ impurities from the bulk material to the outer surface of the specimens as a result of the material obtainment process.

3. To find possible relationships between the thickness of the native oxide film and subsequent corrosion resistance in immersion tests in $3.5 \% \mathrm{NaCl}$.

\section{EXPERIMENTAL PROCEDURE}

\subsection{Test Materials}

The chemical compositions of the tested magnesium alloys (AZ31, AZ80 and AZ91D) are listed in Table 1. Pure $\mathrm{Mg}$ was used as the reference material. $\mathrm{Mg}$ and $\mathrm{AZ31}$ were manufactured in wrought condition and supplied in plates of $3 \mathrm{~mm}$ thickness, whereas AZ80 and AZ91D alloys were manufactured by a casting process and were supplied in the form of billets of 300 and $250 \mathrm{~mm}$ in diameter, respectively. All the materials were supplied by Magnesium Elektron Ltd. The average surface roughness of the samples was $<1 \mu \mathrm{m}$.

\subsection{Preparation and Scanning Electron Microscopy (SEM) Characterisation}

For their metallographic characterisation the specimens were wet ground through successive grades of silicon carbide abrasive papers from P120 to P2000 followed by finishing with $0.1 \mu \mathrm{m}$ diamond paste. Two etching reagents were used: a) Nital, $5 \mathrm{~mL} \mathrm{HNO}_{3}+95 \mathrm{~mL}$ ethanol for up to $15 \mathrm{~s}$, to reveal the constituents and the general microstructure of pure $\mathrm{Mg}, \mathrm{AZ80}$, and AZ91D materials; and b) Vilella reagent, $0.6 \mathrm{~g}$ picric acid $+10 \mathrm{~mL}$ ethanol $+90 \mathrm{~mL} \mathrm{H}_{2} \mathrm{O}$ for $10 \mathrm{~s}$, to reveal the grain boundaries of the AZ31 alloy. The tested specimens were examined by scanning electron microscopy (SEM) using a JEOL JSM-6400 microscope equipped with Oxford Link energy-dispersive X-ray (EDX) microanalysis hardware.

\subsection{Surface Analysis}

Photoelectron spectra were acquired with a Fisons MT500 spectrometer equipped with a hemispherical electron analyser (CLAM 2) and a non-monochromatic magnesium $\mathrm{K} \alpha \mathrm{X}$-ray source operated at $300 \mathrm{~W}$. The specimens were mechanically fixed on small flat discs supported on an XYZ manipulator placed in the analysis chamber. The residual pressure in this ion-pumped analysis chamber was maintained below $10^{-8}$ Torr during data acquisition. Spectra were collected for $20-90 \mathrm{~min}$, depending on the peak intensities, at a pass energy of $20 \mathrm{eV}$, which is typical of high-resolution conditions. The intensities were estimated by calculating the area under each peak after smoothing and subtraction of the S-shaped background and fitting the experimental curve to a mix of Lorentzian and Gaussian lines of variable proportion. Although specimen charging was observed, it was possible to determine accurate binding energies (BE) by referencing to the adventitious $\mathrm{C} 1 \mathrm{~s}$ peak at $285.0 \mathrm{eV}$. Atomic ratios were computed from peak intensity ratios and reported atomic sensitivity factors [48]. The sampled areas were $1 \times 1 \mathrm{~mm}^{2}$. The energy resolution is about $0.8 \mathrm{eV}$.

Bombardment was performed using an EXO5 ion gun, incorporated in the equipment, provided with a scanning unit to track the beam and operating at a voltage of $5 \mathrm{kV}$, an intensity of $10 \mathrm{~mA}$, and a pressure of $1 \times 10^{-7}$ Torr. The sample current was $1 \mu \mathrm{A}$ during bombardment.

In contrast with the preparation for the metallographic characterisation, XPS results for the pure $\mathrm{Mg}$ and $\mathrm{Al}-\mathrm{Mg}$ alloys are the average of the data obtained in duplicate after only cleaning the as-received specimens with distilled water.

\subsection{EIS Measurements}

Electrochemical impedance measurements were conducted in $3.5 \mathrm{wt} . \% \mathrm{NaCl}$ for different times up to 28 days at room temperature $\left(25^{\circ} \mathrm{C}\right)$ and $\mathrm{pH} 5.6$, although the $\mathrm{pH}$ evolved freely during the experiment. Measurements have been carried out just after the first hour and the first day of immersion, and then weekly. An AUTOLAB potentiostat, model PGSTAT30, with frequency response analyser (FRA) software was used. The frequency ranged from $100 \mathrm{kHz}$ to 1 $\mathrm{mHz}$ with 5 points/decade, whereas the amplitude of the sinusoidal potential signal was $10 \mathrm{mV}$ with respect to the open circuit potential (OCP). A three-electrode set-up was 
employed: $\mathrm{Ag} / \mathrm{AgCl}$ and graphite were used as reference and counter electrodes, respectively, and the material under study was the working electrode with an immersed area of $2 \mathrm{~cm}^{2}$. The electrochemical cell used in the tests contained about $400 \mathrm{ml}$ of solution.

\section{RESULTS AND DISCUSSION}

\subsection{Effect of Microstructural Constituents of Magnesium and Mg-Al Alloys on Native Oxide Film Thickness}

\subsubsection{Microstructural Characterisation}

Fig. (1) shows the SEM microstructure of the tested materials. The pure $\mathrm{Mg}$ presented equiaxial grains with an average size of $45 \mu \mathrm{m}$, whereas the grain size in the AZ31 alloy was in the 5-100 $\mu \mathrm{m}$ range. The AZ80 and AZ91D casting alloys revealed two different types of microstructures as a function of the solidification rate. For the AZ80 alloy the solidification process, by solid state transformation, promoted a biphasic or cellular microstructure with an $\alpha-\mathrm{Mg}$ solid solution (grain size of $100 \mu \mathrm{m}$ ) and a discontinuous precipitation of a fine lamellar aggregate, $\alpha-\mathrm{Mg}+\beta$ $\mathrm{Mg}_{17} \mathrm{Al}_{12}$, (grain size in the $100-200 \mu \mathrm{m}$ range) (Fig. 1c). With regard to the AZ91D alloy, lower solidification rates promoted $\alpha-\mathrm{Mg}$ primary dendrites $(40-100 \mu \mathrm{m})$ and a partially divorced eutectic $\alpha-\mathrm{Mg} / \mathrm{Mg}_{17} \mathrm{Al}_{12}$ (coarse particles of 5-60 $\mu \mathrm{m}$ ) in the interdendritic region (Fig. 1d). The cast microstructures for each alloy were homogeneous in all the billets [22,23].

\subsubsection{XPS Analysis of the Spontaneously Formed Native Oxide Film on Magnesium and Mg-Al Alloys}

Table 2, obtained by XPS of the pure magnesium and $\mathrm{Mg}-\mathrm{Al}$ alloy specimens, shows the absence of aluminium on the outer surface of the spontaneously formed native oxide film on all three studied alloys and suggests a strong tendency for the formation of highly hydrated magnesium hydroxide as it has been observed by Mathieu et al. [19]. This effect is limited to a very superficial portion of the native oxide film, since the removal of about $2 \mathrm{~nm}$ (by 10 min of sputtering) has been sufficient to detect the presence of aluminium. It is clear that 10 to $40 \mathrm{~min}$ of AIB does not significantly change the $\mathrm{Al} /(\mathrm{Mg}+\mathrm{Al})$ profile through the bulk material (Table 2). The Al surface enrichment shown in Table 2 is of the same order as that reported elsewhere $[13,19,42,49]$ for $\mathrm{Mg}$-Al alloys with Al contents of $2-10$ wt. $\%$ and suggests a moderate tendency for aluminium segregation, whose concentration can increase by a factor of
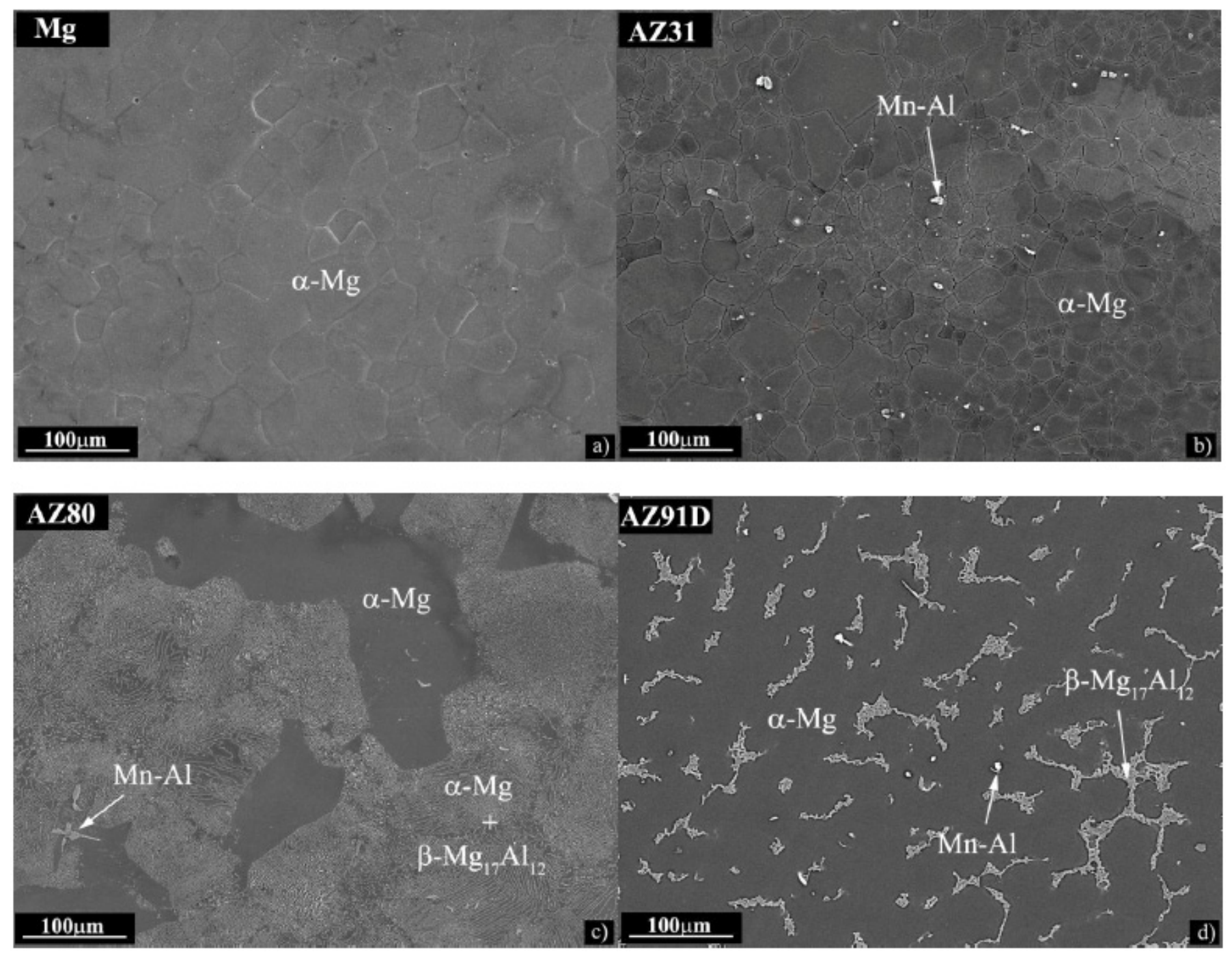

Fig. (1). SEM micrographs of: (a) unalloyed Mg; (b) AZ31 alloy; (c) AZ80 alloy and (d) AZ91D alloy. 
2-3 at most. The $\mathrm{Al} /(\mathrm{Mg}+\mathrm{Al})$ ratios obtained by XPS are not proportional to the Al alloying element content (Table 1), and instead seem to indicate a saturation of the specimen's outer surface with aluminium, around $15 \mathrm{wt} . \%$ according to Table 2.

Due to strong overlap between the second bulk plasmon of the metallic Mg2p peak and the A12p peak observed in our measurements, we have measured the Al2s peak instead of the A12p peak [50]. The evolution of the A12s high resolution XPS spectrum obtained on the native oxide film formed spontaneously on magnesium and $\mathrm{Mg}-\mathrm{Al}$ alloys with AIB time is shown in Fig. (2a-l). The obtained spectra are quite similar and contain two components of similar intensities. One appears at a binding energy of $120.5 \mathrm{eV}$ and is associated with the presence of aluminium in oxide form, while the other appears at approximately $118.5 \mathrm{eV}$ and may be attributed to the presence of aluminium in metallic state (Fig. 2d).

Figs. (3a-d) compare the $\mathrm{C} 1 \mathrm{~s}$ and $\mathrm{O} 1 \mathrm{~s}$ high resolution XPS spectra obtained on the native oxide film formed spontaneously on magnesium (original surface) and after 10 minutes of sputtering. These spectra are representative of the $\mathrm{C} 1 \mathrm{~s}$ and O1s spectra observed on the AZ31, AZ80 and
AZ91D specimens. The C1s spectrum recorded on the outer surface (Fig. 3a) may be fitted to three components with different intensities. The first and most intense is situated at $285.0 \mathrm{eV}$ and may be attributed to the presence of $\mathrm{C}-\mathrm{C} / \mathrm{C}-\mathrm{H}$ groups. At room temperature the surface of any metal, irrespective of its composition, in contact with the atmosphere instantaneously becomes coated with a thin film of $\mathrm{C}-\mathrm{C} / \mathrm{C}-\mathrm{H}$ groups (less than $3 \mathrm{~nm}$ thickness). A second less intense component appears at $286.5 \mathrm{eV}$, which may be associated with the presence of $\mathrm{C}-\mathrm{O}$ groups, and at higher binding energies, $289.0 \mathrm{eV}$, a third component appears which may be associated with the presence of $\mathrm{CO}_{3}{ }^{2-}$ [51]. After 10 minutes of AIB (Fig. 2b) the component associated with the presence of carbonate disappears and this third component shifts $1 \mathrm{eV}$ towards lower binding energies and may be associated with the presence of $\mathrm{O}-\mathrm{C}=\mathrm{O}$ groups below the outer carbonate layer. This suggests that the carbonate layer is limited to the outermost surface.

The O1s spectrum (Fig. 3c) shows the most intense component at $532.2 \mathrm{eV}$. This component may be associated principally with the presence of oxygen in the form of magnesium hydroxide $\left(\mathrm{Mg}(\mathrm{OH})_{2}\right)$ [51]. Two less intense components appear at binding energies of $530.2 \mathrm{eV}$ and

Table 2. Atomic Percentage Observed by XPS on the Outer Surface of the Native Oxide Film Formed on Pure Mg and Mg-Al Alloys After AIB

\begin{tabular}{|c|c|c|c|c|c|c|}
\hline & $\% 0$ & $\% \mathrm{Mg}$ & $\% \mathrm{Al}$ & $\% \mathrm{Ca}$ & $\mathbf{A l} /(\mathbf{A l}+\mathbf{M g})$ & $\mathrm{Ca} /(\mathrm{Ca}+\mathrm{Mg})$ \\
\hline \multicolumn{7}{|l|}{ Mg PURE } \\
\hline +10 MIN AIB & 64 & 32 & 0 & 3 & 0 & 0.09 \\
\hline \multicolumn{7}{|l|}{+20 MIN AIB } \\
\hline \multicolumn{7}{|l|}{ AZ31 } \\
\hline 0 & 80 & 16 & 0 & 2 & 0 & 0.11 \\
\hline +10 MIN AIB & 68 & 25 & 4 & 2 & 0.14 & 0.07 \\
\hline +20 MIN AIB & 69 & 27 & 4 & 0 & 0.13 & 0 \\
\hline \multicolumn{7}{|l|}{ AZ80 } \\
\hline 0 & 83 & 15 & 0 & 2 & 0 & 0.12 \\
\hline +10 MIN AIB & 60 & 31 & 5 & 2 & 0.12 & 0.06 \\
\hline +20 MIN AIB & 55 & 39 & 5 & 0 & 0.11 & 0.00 \\
\hline +30 MIN AIB & 54 & 40 & 5 & 0 & 0.11 & 0.00 \\
\hline +40 MIN AIB & 51 & 42 & 6 & 0 & 0.12 & 0.00 \\
\hline \multicolumn{7}{|l|}{ AZ91D } \\
\hline 0 & 73 & 25 & 0 & 2 & 0 & 0.07 \\
\hline +10 MIN AIB & 55 & 40 & 5 & 0 & 0.11 & 0.00 \\
\hline
\end{tabular}




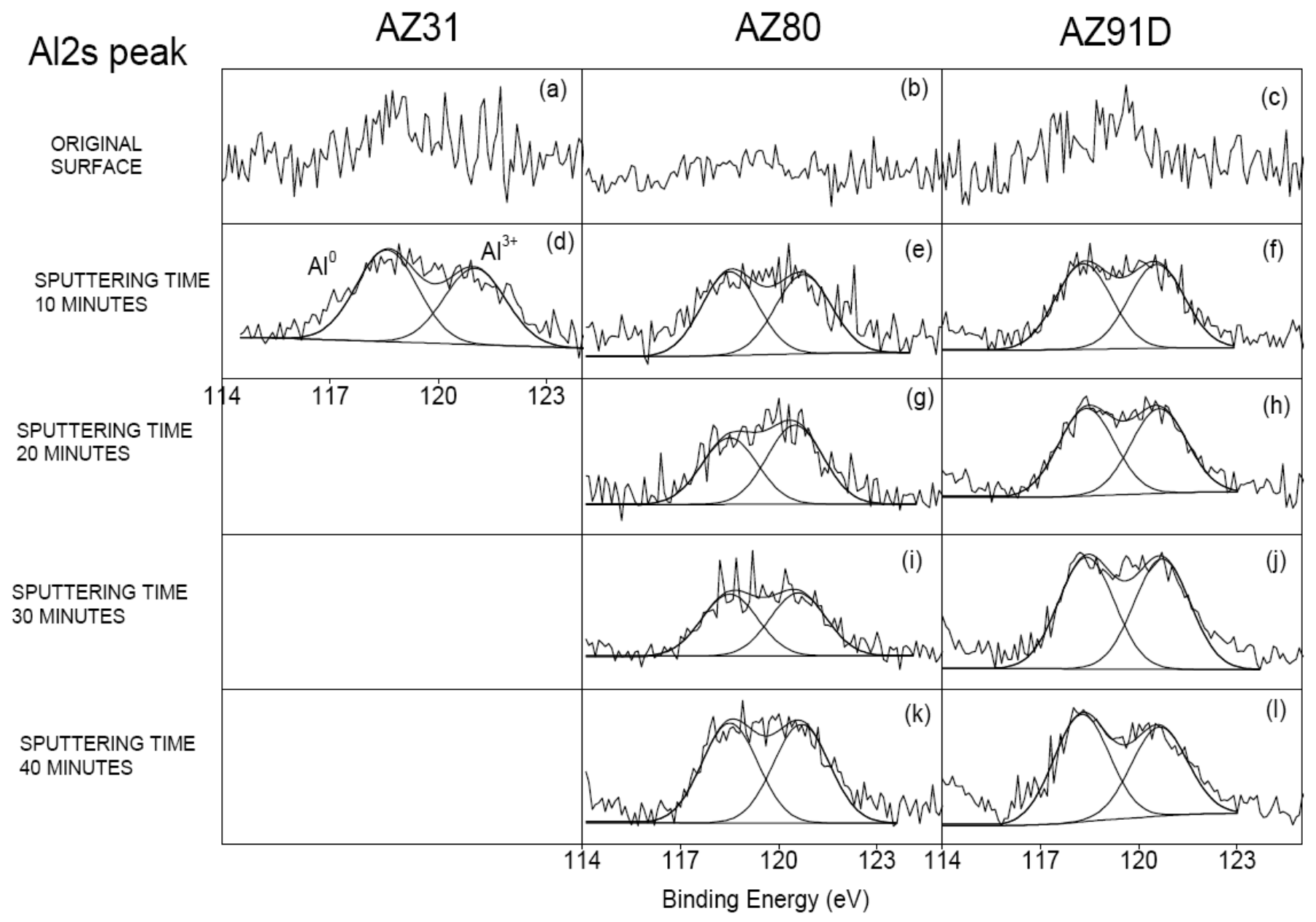

Fig. (2). Comparison of the evolution with AIB time of A12s high resolution spectra obtained on the AZ31, AZ80 and AZ91D alloys.

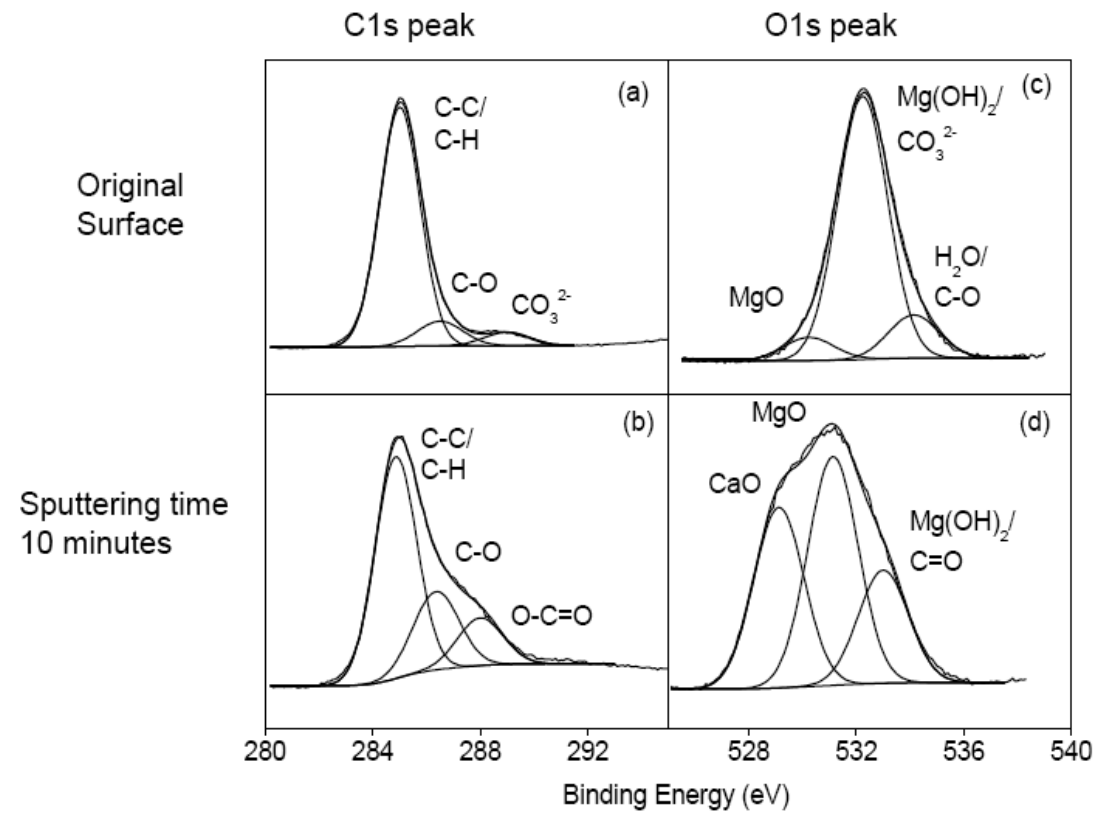

Fig. (3). $\mathrm{C} 1 \mathrm{~s}$ and $\mathrm{O} 1 \mathrm{~s}$ high-resolution XPS spectra on the original surface of pure $\mathrm{Mg}$ specimen and after 10 minutes of sputtering.

$534.2 \mathrm{eV}$ which may be associated with the presence of oxygen in the form of calcium oxide [52] and water or C-O groups. After 10 minutes (Fig. 3d) the second component is seen to shift $1 \mathrm{eV}$ towards lower binding energies and may be associated with the presence of $\mathrm{MgO}$ below the outer $\mathrm{Mg}(\mathrm{OH})_{2}$ layer.

The evolution of the Mg2p high resolution XPS spectrum obtained on the native oxide film formed spontaneously on 
magnesium and $\mathrm{Mg}-\mathrm{Al}$ alloys with $\mathrm{AIB}$ time is shown in Fig. (4a-n). The spectra obtained on the original surface (Fig. 4a-d) are fairly similar, containing one single component at a binding energy of $50.8 \mathrm{eV}$ associated with the presence of magnesium in the form of magnesium hydroxide [51]. Fig. (4e-h) show the spectra obtained after 10 minutes of AIB. The spectra observed on the magnesium (Fig. 4e) and AZ31 (Fig. 4f) show the most intense component at a binding energy of $48.6 \mathrm{eV}$ associated with the presence of magnesium in metallic state and another less intense component at a binding energy of $50.8 \mathrm{eV}$ which may be associated with the presence of magnesium in the form of magnesium oxide (demonstrated by the O1s peak (Fig. 3d)). It is interesting to draw attention to the considerably lower intensity of the metallic magnesium signal on AZ80 (Fig. 4g) and AZ91D (Fig. 4h) than on $\mathrm{Mg}$ (Fig. 4e) and AZ31 (Fig. 4f). This result is interpreted as being due to the greater thickness of the native oxide film in the first two cases.

The thickness of the native oxide film on the surface of the magnesium specimens was calculated using the expression given by Strohmeier [53]:

$\mathrm{d}_{\mathrm{o}}(\mathrm{nm})=\lambda_{\text {oxide }} \sin \theta \ln \left[\mathrm{I}_{\text {oxide }} \mathrm{x} \lambda_{\text {metal }} \times \mathrm{N}_{\mathrm{m}}\right) /\left(\mathrm{I}_{\text {metal }} \times \lambda_{\text {oxide }} \mathrm{x}\right.$ $\left.\left.\mathrm{N}_{\mathrm{o}}\right)+1\right]$

where $d_{o}$ is the thickness of the magnesium oxide layer (in $\mathrm{nm}) ; \theta$ is the photoelectron output angle; $\mathrm{I}_{\text {metal }}$ and $\mathrm{I}_{\text {oxide }}$ are the intensities of the magnesium components in the metallic state and as oxide from the Mg 2 p peak (Fig. 4a-n); $\lambda_{\text {metal }}$ and $\lambda_{\text {oxide }}$ are the mean free paths of photoelectrons in the substrate and the oxide layer; and $\mathrm{N}_{\mathrm{m}}$ and $\mathrm{N}_{\mathrm{o}}$ are the volume densities of magnesium atoms in metal and oxide [54]. The values of $\lambda_{\text {metal }}$ and $\lambda_{\text {oxide }}$ are 3.0 [55] and $2.6 \mathrm{~nm}$ [56], respectively [57], and an $\mathrm{N}_{\mathrm{m}} / \mathrm{N}_{\mathrm{o}}$ ratio of 1.0 was used [58]. On the pure $\mathrm{Mg}$ and AZ31 alloy an important increase was seen in the intensity of the $\mathrm{Mg}^{0}$ signal after 10 minutes of AIB (Fig. 4e, f). However, the fact that the intensity of the component associated with metallic magnesium $\left(\mathrm{I}_{\text {metal }}\right)$ is practically negligible on AZ80 and AZ91D after 10 minutes of AIB (Fig. 4g, h) implies a problem for the thickness determination of the surface oxide layers. The sputtering rate can be estimated by the above equation when metallic $\mathrm{Mg}$ emerged after a certain sputtering time [51]. The sputtering rate of the native oxide films for $\mathrm{Mg}$ and $\mathrm{Mg}$ alloys is about $0.15 \mathrm{~nm} / \mathrm{min}$. This value is close to the sputtering rates obtained by Yao et al. [51] for $\mathrm{Mg}$ in air and previous results from the authors on interstitial-free (IF) steels [59]. Table 3 shows the oxide layer thickness values obtained by multiplying the AIB time necessary for a significant metallic magnesium component to appear in the Mg2p peak (Fig. 4e, $\mathbf{f}, \mathbf{i}, \mathbf{j})$ at the sputtering rate $(0.15 \mathrm{~nm} / \mathrm{min})$. The values obtained are similar to those reported in the literature [43, $44,60]$. It is interesting to note that the thickness of the

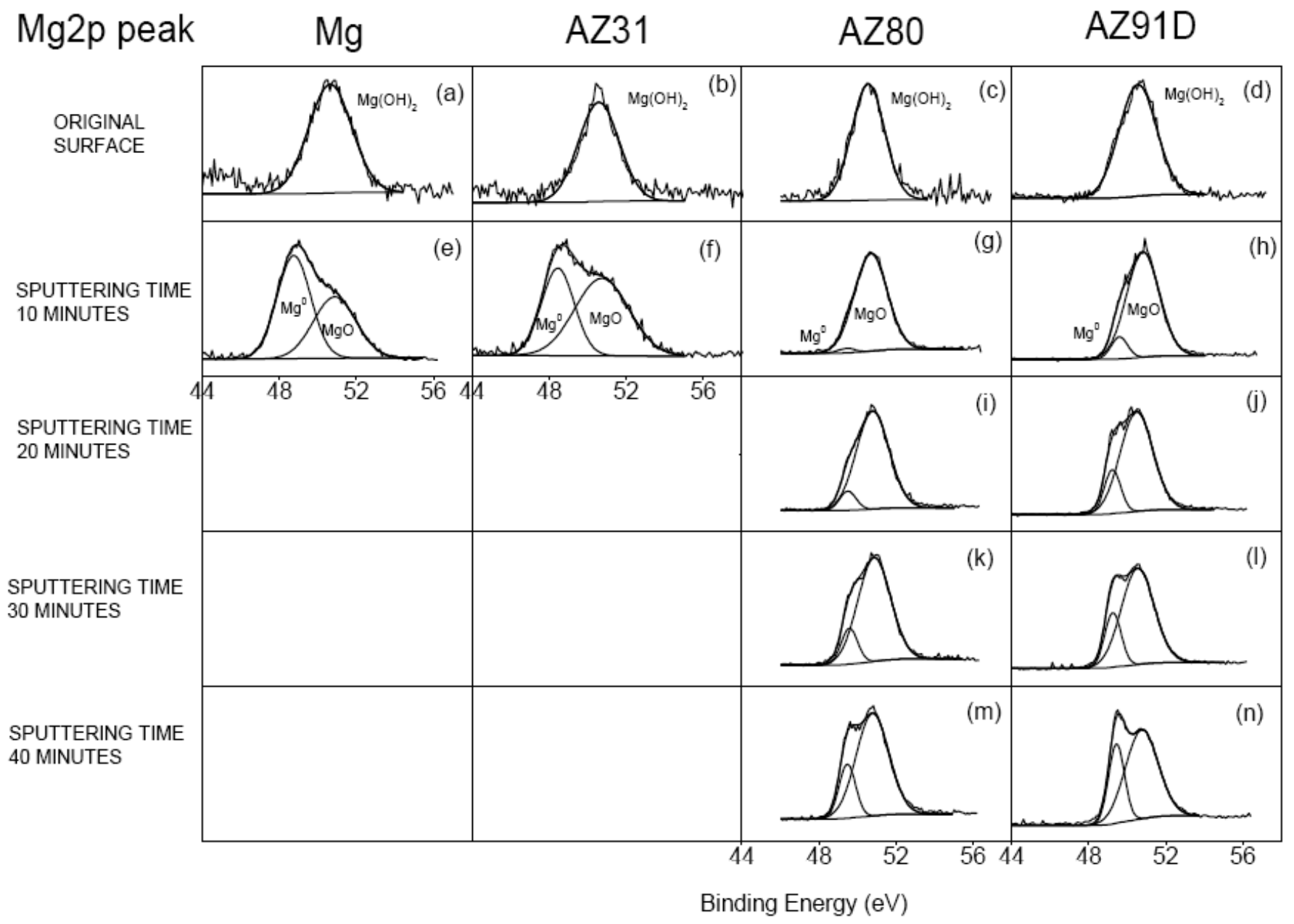

Fig. (4). Evolution with AIB time of the Mg 2p high-resolution XPS spectra for pure Mg, AZ31, AZ80 and AZ91 specimens. 
native oxide film formed spontaneously on AZ80 and AZ91D alloys (obtained after 20 minutes of AIB) is approximately twice that observed on the magnesium and AZ31 specimens (obtained after 10 minutes of AIB) (Table 3). These results show some similarity to those observed by Splinter and McIntyre [46]' who found that the rate of oxide nucleation and growth is enhanced on Mg-Al surfaces compared to pure $\mathrm{Mg}$ surfaces, especially at higher $\mathrm{Al}$ contents. Furthermore, the thickness of the native oxide film on the AZ80 alloy is greater than that observed on the AZ91D alloy (Table 3 ).

Table 3. Native Oxide Film Thickness (nm), Transfer Resistance $\left(R_{t}\right)$ and Corrosion Rate $\left(\mathrm{mg} / \mathrm{cm}^{2} / \mathrm{Day}\right)$

\begin{tabular}{|c|c|c|c|}
\hline Material & $\begin{array}{c}\text { Film } \\
\text { Thickness (nm) }\end{array}$ & $\begin{array}{c}\mathbf{R}_{\mathbf{t}} \\
\left(\mathbf{\Omega . c m} \mathbf{c}^{\mathbf{2}}\right)\end{array}$ & $\begin{array}{c}\text { Corrosion Rate } \\
\left(\mathbf{m g} / \mathbf{c m}^{2} / \mathbf{D a y}\right)\end{array}$ \\
\hline \hline Pure Mg & 2.6 & $\sim 10$ & $\sim 50$ \\
\hline AZ31 & 2.8 & 162 & 3.4 \\
\hline AZ91D & 4.4 & 491 & 1.1 \\
\hline AZ80 & 6.3 & 2900 & 0.2 \\
\hline
\end{tabular}

\subsubsection{Effect of Surface Heterogeneities on Native Oxide Film Thickness}

Thickness differences (of nm order) in the native oxide layer formed spontaneously on metallic materials have been related with the presence of imperfections or heterogeneities where the film is more pervious to the movement of the reaction products $[44,61,62]$. In the commercial magnesium alloys tested in this work there also seems to be a direct relation between the native oxide film thickness and the degree of microstructural complexity of the surface upon which it forms. Thus, Fig. (1) shows a very significant presence of $\beta$ intermetallic phase on the surfaces of AZ80 (Fig. 1c) and AZ91D (Fig. 1d) compared to its absence on AZ31 (Fig. 1b) and pure Mg (Fig. 1a). Chill casting process promoted a biphasic microstructure in the AZ80 alloy, with $\alpha-\mathrm{Mg}$ solid solution and discontinuous precipitation in lamellar form of $\beta$-phase $\left(\mathrm{Mg}_{17} \mathrm{Al}_{12}\right)$ (Fig. 1c). On the other hand, slower cooling casting produced a coarse eutectic dendritic microstructure in the AZ91D alloy and a lower percentage of magnesium surface covered by intermetallic phases (Fig. 1d) [23].

\subsubsection{Effect of Native Oxide Film Thickness on Corrosion Resistance of Commercial Magnesium Alloys Exposed to a $3.5 \% \mathrm{NaCl}$ Solution}

Fig. (5) compares the Nyquist diagrams obtained with (a) AZ31, (b) AZ80 and (c) AZ91D alloy specimens exposed to a $3.5 \% \mathrm{NaCl}$ solution for 1 and 28 days. These diagrams are representative of the plots observed for the AZ31, AZ80 and AZ91D specimens after other testing times. They present one single arc with an inductive tail at the lowest frequencies. The charge transfer resistance values, $R_{t}$, deduced from the HF-MF arc of the Nyquist plots after 1 day of testing for the materials immersed in $3.5 \% \mathrm{NaCl}$ [23] are shown in column 2 of Table 3. Fig. (7, which is lacking information for pure $\mathrm{Mg}$ because this specimen dissolved
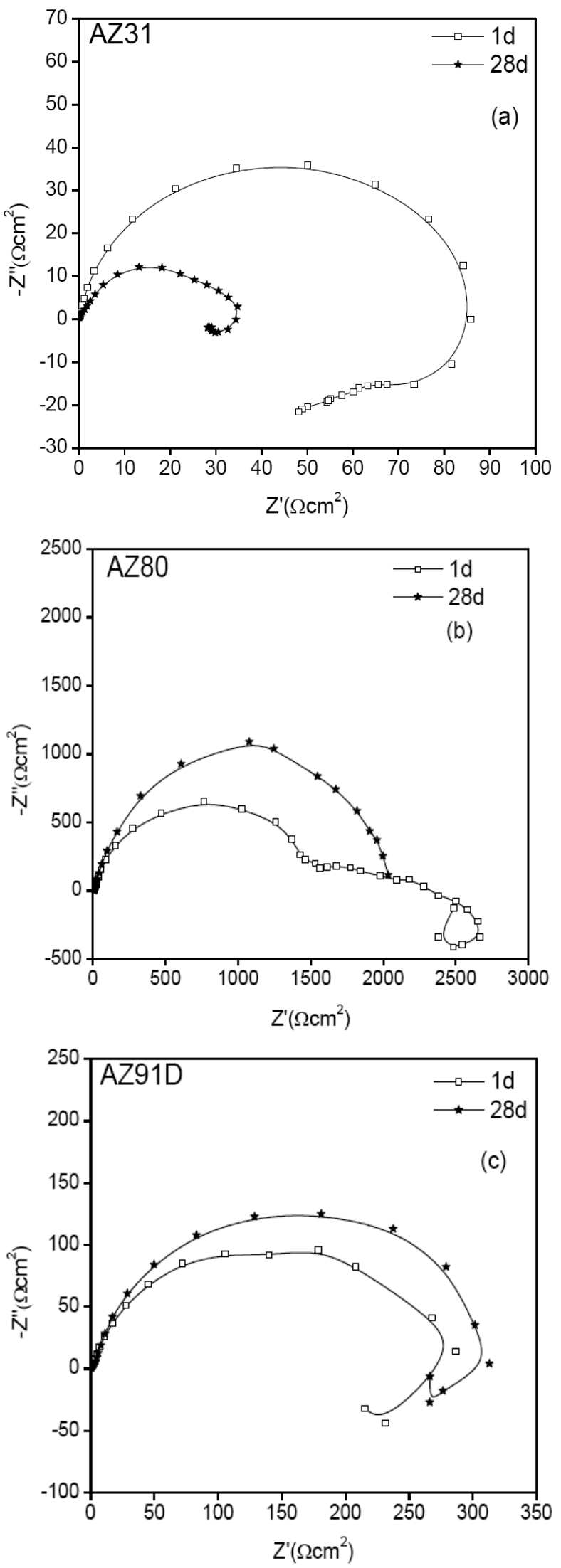

Fig. (5). Nyquist diagram of tested alloys exposed to $3.5 \mathrm{wt} \% \mathrm{NaCl}$ aerated solution after 1 and 28 days: (a) AZ31, (b) AZ80 and (c) AZ91 specimens. 
after just a few days of testing) shows that $R_{t}$ values for the $\mathrm{Mg}$ alloys have changed little over the 28 days of exposure. The exceptionally high corrosion rate of the pure $\mathrm{Mg}$ specimen has yielded very irregular impedance measurements, so the information for this material in Table $\mathbf{3}$ should be viewed as a typical trend rather than a precise datum.

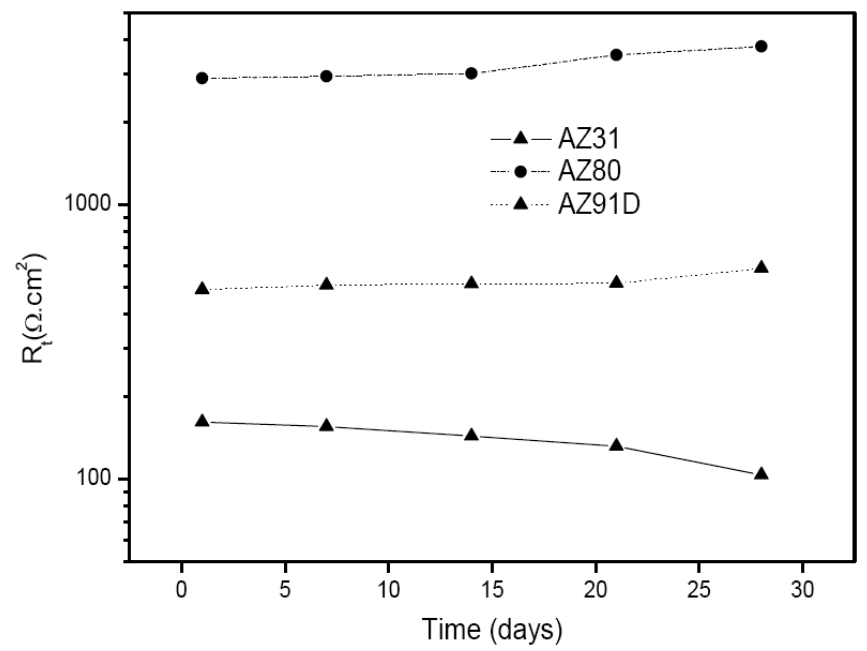

Fig. (6). Evolution of $\mathrm{R}_{\mathrm{t}}$ values with exposure time to $\mathrm{NaCl} 3.5 \mathrm{wt}$ $\%$ on commercial magnesium alloys.

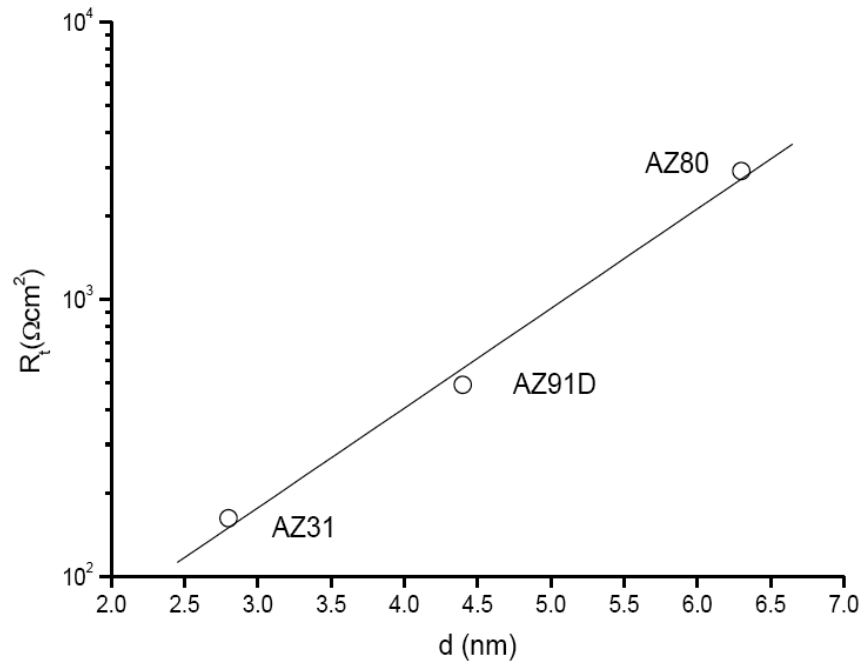

Fig. (7). Correlation between the thickness of the native oxide film (d) and the $R_{t} \cdot$ value

In general, Table 3 shows a clear trend towards an increase in $\mathrm{R}_{\mathrm{t}}$ values and, therefore, a decrease in corrosion rate values as the thickness of the spontaneously formed $\mathrm{MgO}$ film increases. This correspondence between electrochemical values and the native oxide film thickness suggests that the native oxide film formed spontaneously in contact with the atmosphere somehow controls the corrosive attack. However, the doubt arises as to how an oxide film of just a few nanometres in thickness can have a prolonged influence on the corrosion process in saline solution, with much a greater metal dissolution than the thickness of the film. An explanation may be that the film, that is damaged by dissolution, is rapidly repaired or replaced in the aqueous medium by a film of essentially similar characteristics. According to a Cabrera-Mott type mechanism [63], such behaviour may be expected of a film that is sufficiently thin for the electrons to pass through it by a tunnel effect and to react with oxygen or water adsorbed on the outer surface, while at the same times cations enter the film at the metal/film interface. Work by Nordlien et al. $[13,14,45]$ suggests that the original air-formed film is a highly stable form of oxide that preserves its properties when the specimen is exposed to the aqueous environment. The immersed metal could corrode by undermining this oxide film, which is detached from the metallic surface and subsists throughout the corrosion test as a membrane sandwiched between two much thicker porous layers of corrosion products $[13,14,45]$. However, it is difficult to imagine that this membrane, separated from the metallic surface by about $100-200 \mathrm{~nm}$ of corrosion products, can control corrosion rate and thus be directly responsible for the measured $R_{t}$ values. It seems more probable that the original air-formed film, when separated from the metallic surface, is rapidly replaced by a new film formed by direct contact between the metal and the aqueous medium, in a constant process of breakdown and repair. It should also be supposed that the thickness of this film is similar to that of the airformed film, perhaps because the parameters which determine its growth are much more dependent on the characteristics of the tested material (e.g. the amount of metal atoms located at favourable positions, that can jump over the energy barrier into the oxide) than on the medium to which it is exposed.

Imperfections in the solid film formed on the metal surface, in particular pores extending as microchannels from the metal surface to the solution interface, could determine the corrosion rate of the metallic substrate. In this case, the measured $R_{t}$ values per apparent area unit refer to the fraction of the metal exposed to the aqueous solution at the base of these channels. The relation between the values of $R_{t}$ and native oxide film thickness shown in Fig. (7) for the three tested alloys requires further consideration. This relation could be explained, for instance, by considering that the probability of a channel of interconnected pores passing through the entire thickness of a film is an exponential function of the inverse of the thickness [64].

\subsection{Characterisation of calcium impurity segregation on the magnesium surface}

\subsubsection{XPS Analysis of the Surface of Pure Mg and Mg-Al Alloys}

Table 2 shows the element compositions obtained by XPS on the native oxide film formed on pure $\mathrm{Mg}$ and $\mathrm{Mg}$-Al alloys. Attention is drawn to the presence of significant amounts of $\mathrm{Ca}$ on all the studied alloys. The $\mathrm{Ca} /(\mathrm{Ca}+\mathrm{Mg})$ atomic ratios obtained by XPS on magnesium metal reach values close to 0.28 , which could suggest that calcium covers approximately $28 \%$ of the magnesium surface. It is also important to note the absence of significant amounts, within the detection limits of our XPS spectrometer, of other alloying elements such as $\mathrm{Zn}, \mathrm{Mn}$ and $\mathrm{Si}$ on the surface of the studied alloys.

As to the origin of superficial calcium enrichment, one possibility is that $\mathrm{Ca}$ species may have been incorporated in the hydroxide/oxide film that coats the surface during the cleaning process. However, the fact that XPS analysis of the 
outermost surface of pure $\mathrm{Mg}$ (Table 2) shows approximately twice the calcium content of the AZ31, AZ80 and AZ91D alloys exposed to the same cleaning procedure suggests that this is not the origin of the phenomenon. In fact, this proportion is practically identical to that of the calcium content in the bulk of these materials (Table 1), so it seems likely that the observed superficial calcium enrichment is due to the calcium contained as an impurity in the bulk alloy.

Fig. (8) shows the evolution of the $\mathrm{Ca} 2 \mathrm{p}$ high resolution XPS spectra observed on the magnesium surface with AIB time. These spectra are representative of the Ca2p spectra observed on the surfaces of the other materials. The $\mathrm{Ca} 2 p$ high resolution spectrum contains one single doublet with a binding energy of $347.0 \mathrm{eV}$ (Fig. 5a), which is typical of $\mathrm{Ca}$ as $\mathrm{Ca}^{2+}[52]$. Thus the significant $\mathrm{Ca}$ content observed by XPS on the surface of the material would be found as $\mathrm{CaO}$. The literature mentions a tendency for external $\mathrm{CaO}$ layers to form during the annealing process of $\mathrm{MgO}(100)$ crystals containing calcium as an impurity [65-67]. Such enrichment is favoured because the relative Gibbs free energy per equivalent $\left(\Delta \mathrm{G}_{0} / \mathrm{n}\right)$ for the formation of calcium oxide is more positive than that for $\mathrm{MgO}$. The effect is similar to that observed in magnesium alloys with calcium additions as an alloying element [52,68-70].

It is interesting to note that the Ca content observed in the XPS analysis of the outer surface of the Mg specimens tends to decline quickly with AIB time (Table 2 and Fig. 8), probably because the presence of a significant calcium content in oxide form in the magnesium specimens is limited to the outermost surface. This result is similar to that obtained by R. Souda et al. [66] who, working with $\mathrm{MgO}$ crystals including $210 \mathrm{ppm}$ bulk $\mathrm{Ca}$ impurities, found that $\mathrm{Ca}$ ions exist only in the outermost layer and that $\mathrm{Ca}$ enrichment does not take place in the deepest layers.

\section{Ca $2 p$ peak}

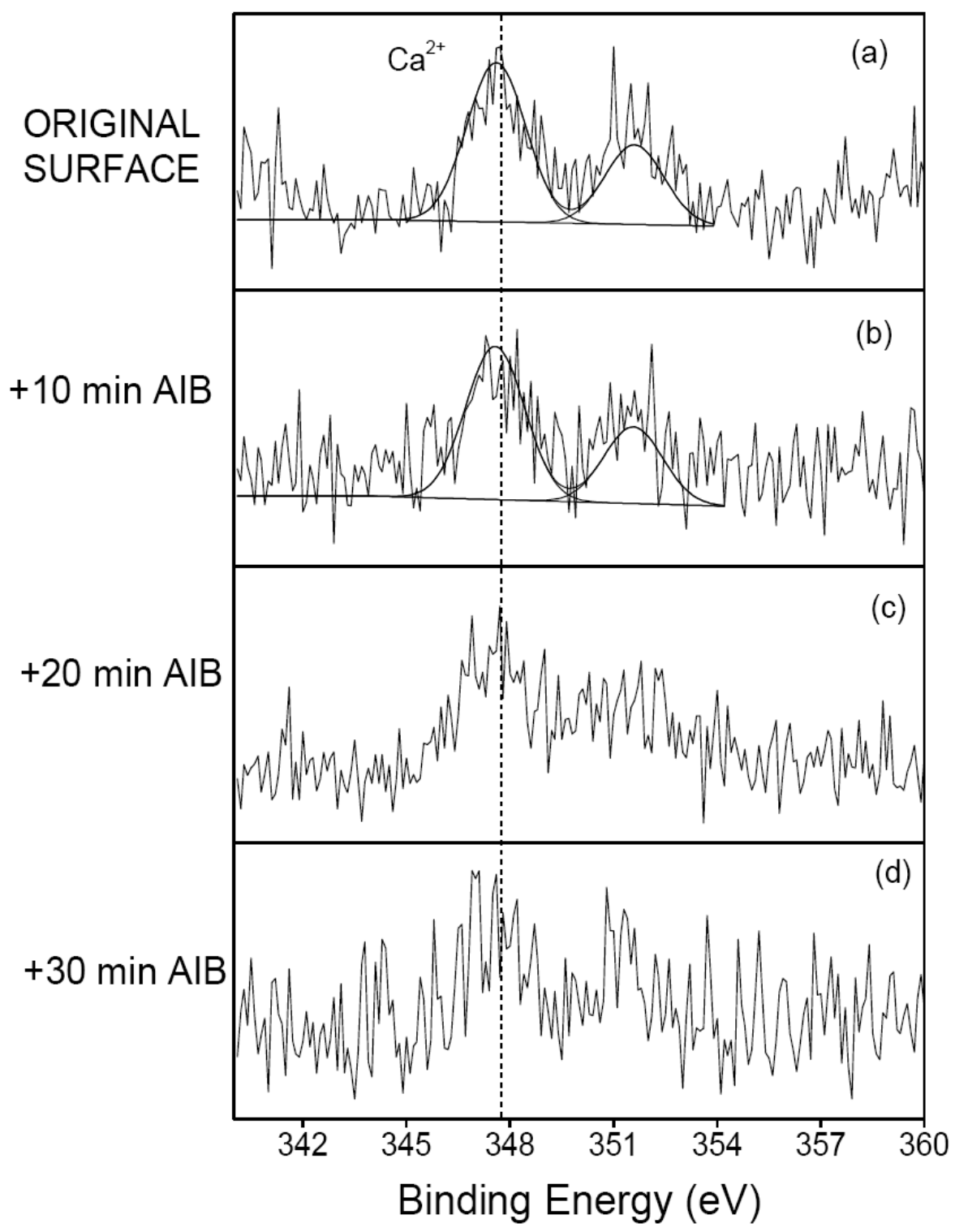

Fig. (8). Evolution with AIB time of the Ca 2p high resolution XPS spectra for pure Mg. 


\subsubsection{EIS Measurements of Effect of Calcium}

It was of interest to study the possible effect of calcium segregation on the protective properties of the native oxide layer formed spontaneously on the pure $\mathrm{Mg}$ specimens. With this intention charge transfer resistance values were obtained after just 1 hour of testing for the materials immersed in a $0.005 \mathrm{M}$ $\mathrm{NaCl}$ solution [71]. The short testing time and the only mildly aggressive solution were selected in view of the exceptionally high corrosion rates of the $\mathrm{Mg}$ specimens. Gentle polishing of the pure $\mathrm{Mg}$ and the AZ31 alloy surfaces was performed with the aim of eliminating the $\mathrm{Ca}$ surface segregation (removed thickness was equivalent to $10 \mu \mathrm{m}$ ). Fig. (9) compares the Nyquist diagrams obtained with the original magnesium and AZ31 alloy specimens without and after gentle polishing. Taking the original surface as the reference (Fig. 9a), polishing tends to decrease the size of the high and medium frequency arc in the Nyquist diagram (Fig. 9b), and thus the charge transfer resistance value $\left(R_{t}\right)$ associated with this arc; the reduction has been around 3 times with pure $\mathrm{Mg}$ and 1.5 times with the AZ31 alloy. Bearing in mind that the thickness of the native oxide film coating on the pure magnesium surface is very thin (Table 3 ) and the absence of aluminium oxides, it may be speculated that the presence of a $\mathrm{CaO}$ layer on the magnesium surface has raised the $R_{t}$ values. These results show a certain similarity with those observed by Jihua et al. [72], indicating that the trace $\mathrm{Ca}$ addition was beneficial to the corrosion resistance improvement of magnesium alloys.

\section{CONCLUSIONS}

1. Notable differences have been seen in the thickness of the native oxide film observed by XPS on the surface of the different studied magnesium-based materials. The greatest thicknesses correspond to the AZ80 and AZ91D alloys, and the smallest to the pure $\mathrm{Mg}$ and the AZ31 alloy. These thickness variations suggest the influence of film imperfections and the degree of microstructural heterogeneity of the studied materials on this parameter.

2. An inverse type relationship was seen between the thickness of the native oxide film formed spontaneously on the surface of the Mg-Al alloys and the corrosion rate of the specimens during the subsequent immersion test. This behaviour seems to suggests a great influence of the thin films formed by electron tunnelling on the corrosion rate.

3. On the pure $\mathrm{Mg}$ and the studied $\mathrm{Mg}-\mathrm{Al}$ alloys a strong tendency was seen for the calcium impurity to segregate, mainly as $\mathrm{CaO}$, to the outermost surface of the specimens; the atomic fraction of $\mathrm{Ca}$ segregated being almost 1500 times the atomic fraction in the bulk.

4. On all three studied Mg-Al alloys, moderate segregation of the Al alloying element towards a surface region immediately below the outermost surface layer of the native oxide film has been observed. The segregated aluminium content is very similar in all three studied alloys and independent of the aluminium concentration in the bulk alloy, which seems to suggest a saturation of the metallic surface in this element.

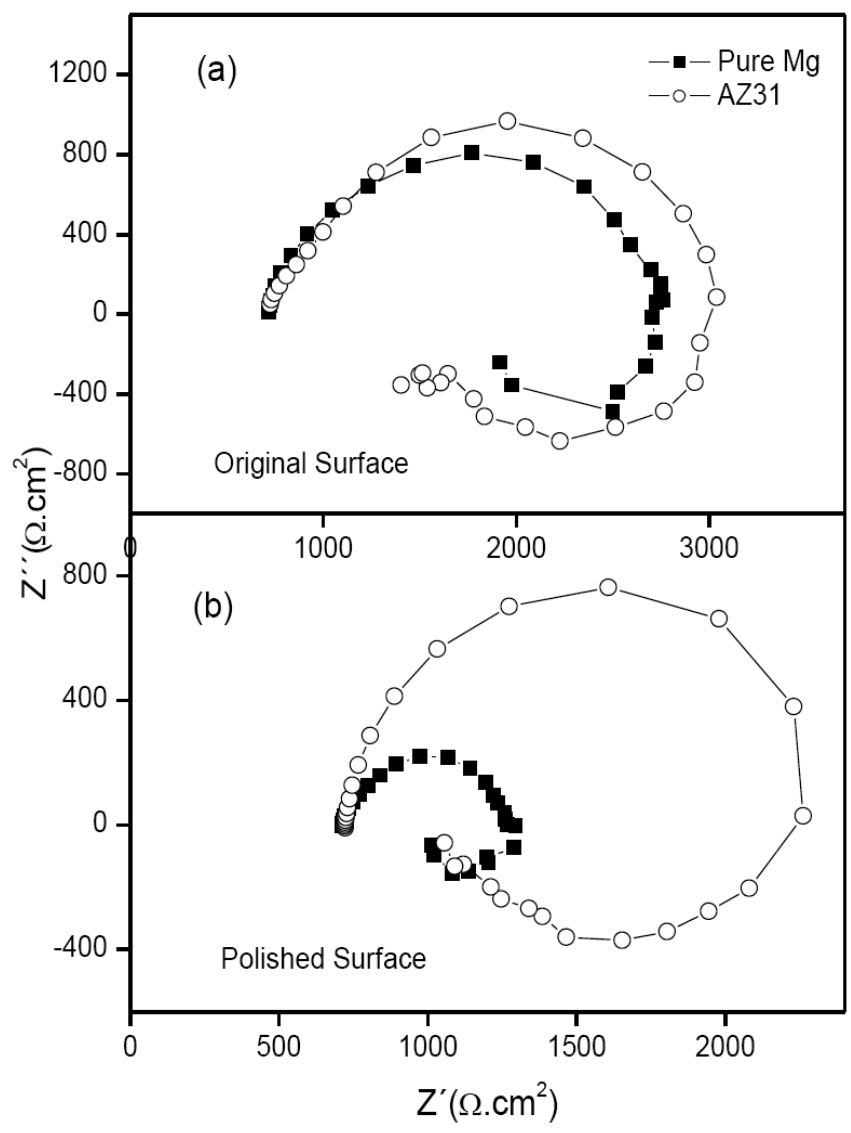

Fig. (9). Nyquist diagrams of the pure $\mathrm{Mg}$ and AZ31 alloy tested after exposure to $0.005 \mathrm{M} \mathrm{NaCl}$ aerated solution for $1 \mathrm{~h}$. Original surface (a) and polished surface (b).

\section{ACKNOWLEDGEMENTS}

This work has been financially supported by the Ministry of Science and Innovation of Spain (MAT2009-13530 and MAT2006-04486 Projects).

\section{REFERENCES}

[1] Song GL, Atrens A. Understanding magnesium corrosion - A framework for improved alloy performance. Adv Eng Mater 2003; 5: 837-58.

[2] Song GL, Atrens A. Corrosion mechanisms of magnesium alloys Adv Eng Mater 1999; 1: 11-33.

[3] Song GL, Atrens A. Recent insights into the mechanism of magnesium corrosion and research suggestions. Adv Eng Mater 2007; 9: 177-83.

[4] Song GL, Atrens A, Wu X, Zhang B. Corrosion behaviour of AZ21, AZ501 and AZ91 in sodium chloride. Corrosion Sci 1998; 40: 1769-91.

[5] Song GL, Atrens A, Stjohn D, Naim J, Li Y. The electrochemical corrosion of pure magnesium in $1 \mathrm{~N} \mathrm{NaCl}$. Corrosion Sci 1997; 39: $855-75$.

[6] Lindstrom R, Svenson JE, Johansson LG. The influence of carbon dioxide on the atmospheric corrosion of some magnesium alloys in the presence of NaCl. J Electrochem Soc 2002; 149: B103-B107.

[7] Lindstrom R, Johansson LG, Thompson GE, Skeldon P, Svensson JE. Corrosion of magnesium in humid air. Corrosion Sci 2004; 46: 1141-58.

[8] Jonsson M, Persson D, Gubner R. The initial steps of atmospheric corrosion on magnesium alloy AZ91D. J Electrochem Soc 2007; 154: C684-C691.

[9] Jonsson M, Persson D, Thierry D, Corrosion product formation during $\mathrm{NaCl}$ induced atmospheric corrosion of magnesium alloy AZ91D. Corrosion Sci 2007; 49: 1540-58. 
[10] Nordlien JH, Ono S, Masuko N, Nisancioglu K, Morphology and structure of oxide-films formed on magnesium by exposure to air and water. J Electrochem Soc 1995; 142: 3320-2.

[11] Baril G, Pebere N. The corrosion of pure magnesium in aerated and deaerated sodium sulphate solutions. Corrosion Sci 2001; 43: 47184.

[12] Ballerini G, Bardi U, Bignucolo R, Ceraolo G. About some corrosion mechanisms of AZ91D magnesium alloy. Corrosion Sci 2005; 47: 2173-84.

[13] Nordlien JH, Nisancioglu K, Ono S, Masuko N. Morphology and structure of oxide films formed on $\mathrm{MgAl}$ alloys by exposure to air and water. J Electrochem Soc 1996; 143: 2564-72.

[14] Nordlien JH, Nisancioglu K, Ono S, Masuko N. Morphology and structure of water-formed oxides on ternary $\mathrm{MgAl}$ alloys. J Electrochem Soc 1997; 144: 461-6.

[15] Lunder O, Lein JE, Aune T K, Nisancioglu K. The role of $\mathrm{Mg}$ 17A112 phase in the corrosion of $\mathrm{Mg}$ alloy $\mathrm{AZ91}$. Corrosion 1989; 45: 741-8.

[16] Song GL, Atrens A, Dargusch M. Influence of microstructure on the corrosion of diecast AZ91D. Corrosion Sci 1999; 41: 249-73.

[17] Lindstrom R, Johansson LG, Svensson JE. The influence of $\mathrm{NaCl}$ and $\mathrm{CO} 2$ on the atmospheric corrosion of magnesium alloy AZ91. Mater Corrosion 2003; 54: 587-94.

[18] Ambat R, Aung NN, Zhou W. Evaluation of microstructural effects on corrosion behaviour of AZ91D magnesium alloy. Corrosion Sci 2000; 42: 1433-55.

[19] Mathieu S, Rapin C, Steinmetz J, Steinmetz P. A corrosion study of the main constituent phases of AZ91 magnesium alloys. Corrosion Sci 2003; 45: 2741-55.

[20] Shi Z, Song GL, Atrens A. Influence of the $\beta$ phase on the corrosion performance of anodized coating on magnesiumaluminium. Corrosion Sci 2005, 47: 2760-77.

[21] Makar GL, Kruger J. Corrosion studies of rapidly solidified magnesium alloys. J Electrochem Soc 1990; 137: 414-21.

[22] Pardo A, Merino MC, Coy AE, Arrabal R, Viejo F, Matykina E. Corrosion behaviour of magnesium/aluminium alloys in $3.5 \mathrm{wt}$. \% $\mathrm{NaCl}$. Corrosion Sci 2008; 50: 823-34.

[23] Pardo A, Merino MC, Coy AE, Viejo F, Arrabal R, Feliu Jr S. Influence of microstructure and composition on the corrosion behaviour of $\mathrm{Mg} / \mathrm{Al}$ alloys in chloride media. Electrochim Acta 2008; 53: 7890-902

[24] Zhao MC, Schmutz P, Brunner S, Liu M, Song GL, Atrens A. An exploratory study of the corrosion of $\mathrm{Mg}$ alloys during interrupted salt spray testing. Corrosion Sci 2009; 51:1277-92.

[25] Liu M, Uggowitzer PJ, Nagasekhar AV, et al. Calculated phase diagrams and the corrosion of die-cast $\mathrm{Mg}-\mathrm{Al}$ alloys. Corrosion Sci 2009; 51:602-19.

[26] Peng LM, Chang JW, Guo XW, Atrens A, Ding WJ, Peng YH. Influence of heat treatment and microstructure on the corrosion of magnesium alloy Mg-10Gd-3Y-0.4Zr. J Appl Electrochem 2009; 39: 913-20.

[27] Zhao MC, Liu M, Song GL, Atrens A. Influence of $\mathrm{pH}$ and chloride ion concentration on the corrosion of $\mathrm{Mg}$ alloy ZE41. Corrosion Sci 2008; 50:3168-78.

[28] Zhao MC, Liu M, Song GL, Atrens A. Influence of the beta-phase morphology on the corrosion of the Mg alloy AZ91. Corrosion Sci 2008; 50:1939-53.

[29] Bender S, Goellner J, Atrens A. Corrosion of AZ91 in $1 \mathrm{~N} \mathrm{NaCl}$ and the mechanism of magnesium corrosion. Adv Eng Mater 2008; 10: $583-7$

[30] Zhao MC, Liu M, Song GL, Atrens A. Influence of microstructure on corrosion of as-cast ZE41. Adv Eng Mater 2008; 10:104-11.

[31] Zhao MC, Liu M, Song GL, Atrens A. Influence of homogenization annealing of AZ91 on mechanical properties and corrosion behavior. Adv Eng Mater 2008; 10: 93-03.

[32] Liu M, Qiu D, Zhao MC, Song GL, Atrens A. The effect of crystallographic orientation on the active corrosion of pure magnesium. Scr Mater 2008; 58: 421-24.

[33] Wu G, Fan Y, Atrens A, Zhai C, Ding W. Electrochemical behavior of magnesium alloys AZ91D, AZCe2, and AZLa1 in chloride and sulfate solutions. J Appl Electrochem 2008; 38: 251-7.

[34] Chang JW, Guo XW, Fu PH, et al. Comparison of the corrosion behaviour in $5 \% \mathrm{NaCl}$ solution of $\mathrm{Mg}$ alloys NZ30K and AZ91D. $\mathrm{J}$ Appl Electrochem 2008; 38: 207-14.

[35] Seyeux A, Liu M, Schmutz P, Song GL, Atrens A, Marcus P. ToFSIMS depth profile of the surface film on pure magnesium formed by immersion in pure water and the identification of magnesium hydride. Corrosion Sci 2009; 51: 1833-86.

[36] Liu M,. Zanna S, Ardelean H, et al. A first quantitative XPS study of the surface films formed, by exposure to water, on $\mathrm{Mg}$ and on the Mg-Al intermetallics: Al3Mg2 and Mg17Al12. Corrosion Sci 2009 ; 51: 1115-27.

[37] Ardelean H, Frateur I, Marcus P. Corrosion protection of magnesium alloys by cerium, zirconium and niobium-based conversion coatings. Corrosion Sci 2008 ; 50 :1907-18.

[38] Santamaria M, Di Quarto F, Zanna S, Marcus P. Initial surface film on magnesium metal: A characterization by X-ray photoelectron spectroscopy (XPS) and photocurrent spectroscopy (PCS). Electrochim Acta 2007; 53: 1314-24.

[39] Fourier V, Marcus P, Olefjord I. Oxidation of magnesium. Surf Interface Anal 2002; 34: 494-7.

[40] Feliu Jr S, Pardo A, Merino MC, Coy AE, Viejo F, Arrabal R. Correlation between the surface chemistry and the atmospheric corrosion of AZ31, AZ80 and AZ91D magnesium alloys. Appl Surf Sci 2009; 255: 4102-8

[41] Feliu Jr S, Merino MC, Arrabal R, Coy AE, Matykina E. XPS study of the effect of aluminium on the atmospheric corrosion of the AZ31 magnesium alloy. Surf Interface Anal 2009; 41:143-50.

[42] Kim J, Wong KC, Wong PC, Kulinich SA, Metson JB, Mitchell KAR. Characterization of AZ91 magnesium alloy and organosilane adsorption on its surface. Appl Surf Sci 2007; 253: 4197-207.

[43] Fotea C, Callaway J, Alexander MR. Characterisation of the surface chemistry of magnesium exposed to the ambient atmosphere. Surf Interface Anal 2006 ; 38: 1363-71.

[44] Mc Intyre NS, Chen C. Role of impurities on Mg surfaces under ambient exposure conditions. Corrosion Sci 1998; 40: 1679-709.

[45] Nordlien JH, Ono S, Masuko N, Nisancioglu K. A TEM investigation of naturally formed oxide films on pure magnesium. Corrosion Sci 1997; 39: 1397-414.

[46] Splinter SJ, McIntyre NS. The initial interaction of water-vapor with Mg-Al alloy surfaces at room-temperature. Surf Sci 1994; 314: 157-71.

[47] Feliu Jr S, Barranco V. XPS study of the surface chemistry of conventional hot-dip galvanised pure $\mathrm{Zn}$, galvanneal and $\mathrm{Zn}-\mathrm{Al}$ alloy coatings on steel. Acta Mater 2003; 51: 5413-24.

[48] Wagner CD, Davis LE, Zeller MV, Taylor JA, Raymond RH, Gale L. Empirical atomic sensitivity factors for quantitative-analysis by electron-spectroscopy for chemical-analysis. Surf Interface Anal 1981; 3: 211-25.

[49] Unigovski YB, Gutman EM. Surface morphology of a die-cast Mg alloy. Appl Surf Sci 1999; 153: 47-52.

[50] Jeurgens LPH, Vinodh MS, Mittemajier EJ. Quantitative analysis of multi-element oxide thin films by angle-resolved XPS: Application to ultra-thin oxide films on MgAl substrates. Appl Surf Sci 2006; 253: 627-38

[51] Yao HB, Li Y, Wee ATS. An XPS investigation of the oxidation/corrosion of melt-spun Mg. Appl Surf Sci 2000; 158: 112-9.

[52] Lee DB, Song L, Kim YJ. Effect of $\mathrm{Ca}$ and $\mathrm{CaO}$ on the High Temperature Oxidation of AZ91D Mg Alloys. Mater Trans 2008; 49: $1084-8$

[53] Strohmeier BR, An ESCA method for determining the oxide thickness on aluminum-alloys. Surf Interface Anal 1990; 15: 51-6.

[54] Chen C, Splinter SJ, Do T, McIntyre NS. Measurement of oxide film growth on $\mathrm{Mg}$ and $\mathrm{Al}$ surfaces over extended periods using XPS. Surf Sci 1997; 382: L652-L657.

[55] Tanuma S, Powell CJ, Penn DR. Calculations of electron inelastic mean free paths .2. Data for 27 elements over the 50-2000-ev range. Surf Interface Anal 1991; 17: 911-26.

[56] Akkerman A, Boutboul T, Breskin A, Chechik R, Gibrekhterman A, Lifshitz Y. Inelastic electron interactions in the energy range 50 $\mathrm{eV}$ to $10 \mathrm{keV}$ in insulators: Alkali halides and metal oxides. Phys Stat Sol (b) 1996; 198: 769-84.

[57] Powell CJ, Jablonski A, NIST Electron Inelastic-Mean-Free-Path Database, SRD 71, Gaithersburg: Dept of Commerce (US), National Institute of Standards and Technology 2000.

[58] Do T, Splinter SJ, Chen C, McIntyre NS. The oxidation kinetics of Mg and Al surfaces studied by AES and XPS. Surf Sci 1997; 387 192-8.

[59] Feliu Jr S , Perez- Revenga ML. Effect of the presence of alloying elements in interstitial-free and low-carbon steels on their surface 
composition after annealing in reducing atmospheres (dew point $=$ -30 degrees C). Met Mater Trans 2004; 35A: 2039-50.

[60] Asami K, Ono S. Quantitative X-ray photoelectron spectroscopy characterization of magnesium oxidized in air. J Electrochem Soc 2000; 147: 1408-13.

[61] Feliu Jr S, Bartolomé MJ. Influence of alloying elements and etching treatment on the passivating films formed on aluminium alloys. Surf Interface Anal 2007; 39: 304-16.

[62] Czerwinski F. The oxidation behaviour of an AZ91D magnesium alloy at high temperatures. Acta Mater 2002; 50: 2639-54.

[63] Cabrera N, Mott NF, Theory of the oxidation of metals. Rep Prog Phys 1948; 12:163-84

[64] Evans UR., An Introduction to Metallic Corrosion. London: Arnold 1948.

[65] Ota H, Sakai K, Aoki R, Ikeyima N, Hara S, Superstructure observation on a $\mathrm{MgO}(100)$ surface. Surf Sci 1996; 357-358: 150-4.

[66] Souda R, Hwang Y, Aizawa T, Hayami W, Oyoshi K. Ca segregation at the $\mathrm{MgO}(001)$ surface studied by ion scattering spectroscopy. Surf Sci 1997; 387: 136-41.
[67]

McCune RC, Wynblatt P. Calcium segregation to a magnesiumoxide (100) surface. J Am Ceram Soc 1983; 66: 111-7.

[68] You BS, Park WW, Chung IS. The effect of calcium additions on the oxidation behavior in magnesium alloys. Scripta Mater 2000 42: 1089-94.

[69] Masaki K, Ochi Y, Kakiuchi T, et al. High cycle fatigue property of extruded non-combustible $\mathrm{Mg}$ alloy AMCa602. Mater Trans 2008; 49: 1148-56.

[70] Ha SH, Lee JK, Kim SK. Effect of $\mathrm{CaO}$ on oxidation resistance and microstructure of pure Mg. Mater Trans 2008; 49: 1081-3.

[71] Lamaka SV, Montemor MF, Galio AF, et al. Novel hybrid sol-gel coatings for corrosion protection of AZ31B magnesium alloy. Electrochim Acta 2008; 53: 4773-83.

[72] Jihua C, Zhenhua C, Hongge Y, Fuquan Z, Yingliang C. Effects of $\mathrm{Sn}$ and $\mathrm{Ca}$ additions on microstructure, mechanical properties, and corrosion resistance of the as-cast $\mathrm{Mg}-\mathrm{Zn}$-Al-based alloy. Mater Corrosion 2008; 59:934-41.

(C) Feliu Jr. et al.; Licensee Bentham Open.

This is an open access article licensed under the terms of the Creative Commons Attribution Non-Commercial License (http:/creativecommons.org/licenses/by-nc/ $3.0 /$ ) which permits unrestricted, non-commercial use, distribution and reproduction in any medium, provided the work is properly cited. 